\title{
Newer Employment Possibilities for Women in India
}

\author{
Jasmeet Kaur $^{1}$ and Jai Jayant ${ }^{2}$ \\ ${ }^{1}$ Research Scholar, Department of Management, Himgiri Zee University, Dehradun, \\ Uttarakhand. \\ ${ }^{2}$ Assistant Professor, Department of Management, Himgiri Zee University, Dehradun, \\ Uttarakhand. \\ jasmeetkaur211995@gmail.com
}

\begin{abstract}
Pandemic of Covid-19 has marked new beginning of the many human endevours in the cultural, social, medical as well as employbility aspects. New phenomemnon such as work from home, digitization and online dependence has not only caused several problems and detriments for the working sector but also has created possiblities for newer version of employements. In India, women majorly are involved in each and every aspects of life but in an unorganized way. Need of the hour is to generate newer and novel working structures especially for women in this post covid era of the world. All the governmental and non governmental authorities and bodies must come together with this will and try to cashout such situation which will not only provide more and more employement to the women of India but also work in favour of several societal and cultural issues such as equity, equality, upliftment and empowerment for women in India. In this research paper we will propose several newer possiblities for women in post covid era and study the current situation of women in working sectors in India.
\end{abstract}

Keywords: Covid-19, Women, Employment, Digitization, Entreprenuership.

\section{INTRODUCTION}

India as the economy has undergone a substantial transformation since its independence. Agriculture now accounts for $1 / 3^{\text {rd }}$ of the gross GDP of the nation and there exist wide range of industries and services today. India has really evolved with the time. This run was however no smooth, its suffered greatly during 'Persian Gulf Crisis' i.e. during the period of late 80s and early 90s. This crisis generated the need of 'loosening governmental regulations', particularly private businesses. India as already known is a multifaceted society where everyone is ranked according to their power, class, caste, and wealth. Situation of Women however is much more vulnerable. They are expected to be chaste and modest in all actions that constraints their 
capabilities and performance in the workplace. Women generally are confined to houses thus restricting their mobility and further more face seclusion. There is paradoxical situation where family suffers financially, although there is need for women going out and work but then too women's participation is viewed as danger to their chastity, subtly wrong, inappropriate and against women virtue. Even professional women find discrimination as a prevalent feature. $2 / 3^{\text {rd }}$ of working women in a study felt that they had to work harder to receive same benefits and comparably employed men. [1-3]

India is the first among countries to give women equal franchise and has a highly credible record with regard to the enactment of laws to protect and promote the interests of women, but women continue to be denied economic, social and legal rights and privileges. Though they are considered to be equal partners in progress, yet they remain subjected to repression, marginalization and exploitation. It has been advocated by many researchers (Amartya Sen, 1990) that independent earning opportunities reduce the economic dependence of woman on men and increase her bargaining power in the family. This bargaining power depends on the nature of work she is employed in. But the income earning activities increase the workload of a woman unless the man accepts an increased share in domestic work. Since globalization is introducing technological inputs, women are being marginalized in economic activities, men traditionally being offered new scopes of learning and training.[2-4]

\subsection{Women: The hidden economic strength of the country}

Although most women in India work and contribute to the economy in one form or another, much of their work is not documented or accounted for in official statistics. Women plow fields and harvest crops while working on farms, women weave and make handicrafts while working in household industries, women sell food and gather wood while working in the informal sector. Additionally, women are traditionally responsible for the daily household chores (e.g., cooking, fetching water, and looking after children). Although the cultural restrictions women face are changing, women are still not as free as men to participate in the formal economy. In the past, cultural restrictions were the primary impediments to female employment now however; the shortage of jobs throughout the country contributes to low female employment as well. The Indian census divides workers into two categories: "main" and "marginal" workers. Main workers include people who worked for 6 months or more during the year, while marginal workers include those who worked for a shorter period. Many of these workers are agricultural laborers. Unpaid farm and family enterprise workers are supposed to be included in either the main worker or marginal worker category, as appropriate. Women account for a small proportion of the formal Indian labor force, even though the number of female main workers has grown faster in recent years than that of their male counterparts.[2-6]

Conditions of working women in India have improved considerably in the recent years. Ironically, despite the improvement in their status, they still find themselves dependent on men. It is because of the fact that man in patriarchal society has always wielded economic independence and power to take decision. Since the working woman earns an independent income in the same patriarchal set- 
up, where the basic infrastructure of society has hardly changed, though her own role within the same structure is passing through a transitional phase, it is but natural that she would remain vulnerable to exploitation even in her economically independent state. Society perhaps yet needs to accord due recognition to women to take the lead role and women, at the same time; need to be oriented vigorously towards assuming this role in the society.[6-9]

\section{OVERVIEW : FEMALE LABOUR FORCE PARTICIPATION}

A New India can be built only when women have access to equal social and economic opportunities. In this context, the statistics on Female Labor Force Participation (FLFP) are worrying to say the least. According to ILO estimates, India's FLFP has declined from 32\% in 2005 to $21 \%$ in 2019. Economic Survey 2020 estimates that $60 \%$ of women between 15-59 years are engaged in full-time housework as compared to 1\% of males. Between 2011 and 2015, the unemployment rate in India rose from $3 \%$ to $5 \%$, and is estimated to have further increased to $7 \%$ by the end of 2018. Making matters worse, only 4.3 million jobs have been created per year since 2012, even though 12 million people enter the workforce every year. While the dire condition of employment in India has only recently gained attention in the national discourse, the problem had existed for at least two decades. The only difference is of the gender of the unemployed. As per the calculations done by the Centre for Monitoring Indian Economy, one of the leading business and economic database, the FLFPR further declined to 10\% for the period of May to August in 2018. Meanwhile, as per a McKinsey report, men have been employed in $90 \%$ of the 36 million additional jobs created in India since 2015

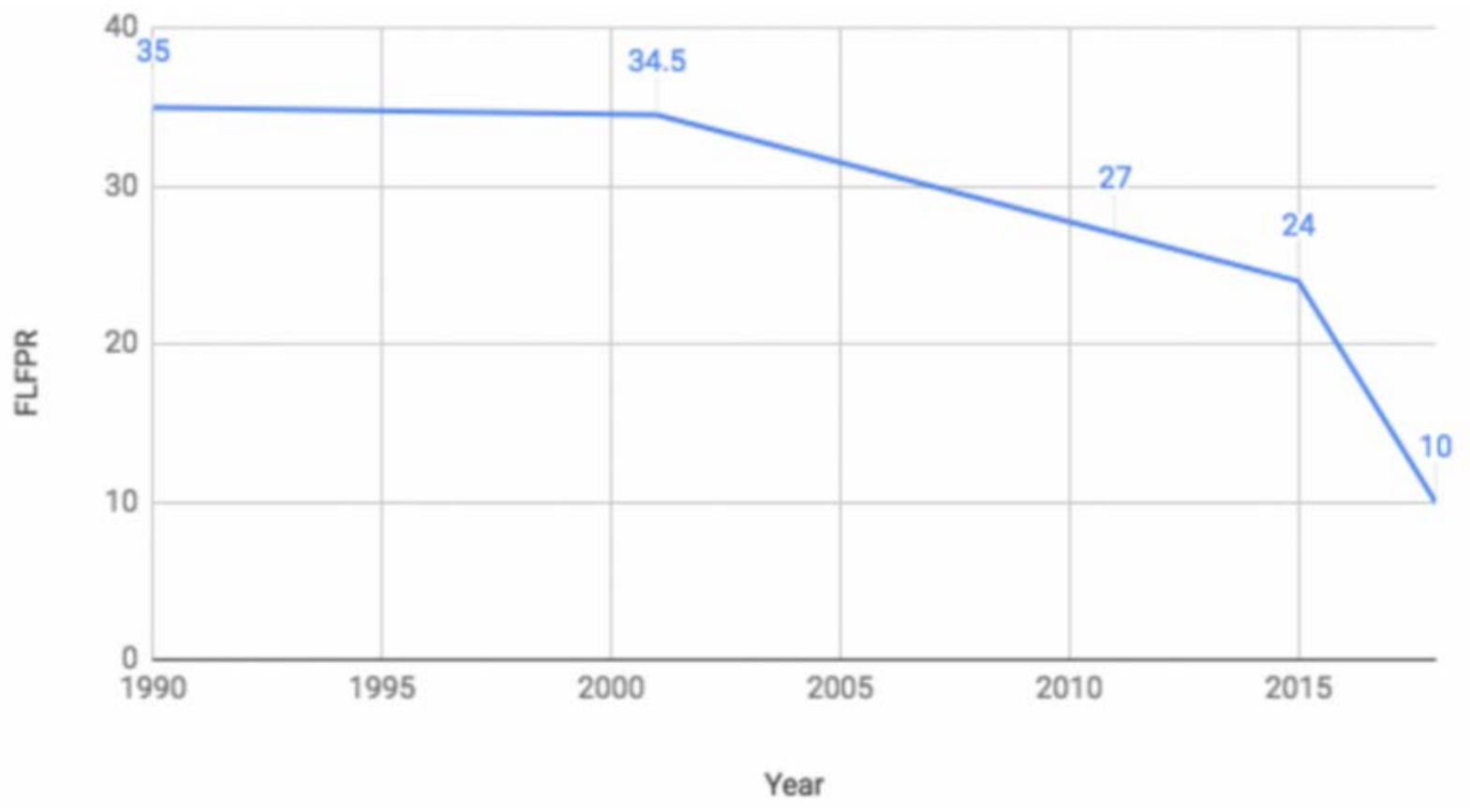

Fig 1. Female Labour force Participation Rate, 1990 to 2019 
The causes behind the disparity are commonly attributed to the gender pay gap or the lack of safety in the workplace. In addition to factors like a decline in job creation and skills mismatch that affects the entire labour force in the country, women also face unique challenges that convolute the problem further. These challenges include,

- Lack of agency - women do not have the freedom or support to make decisions regarding their education or career. This limits their ability to pursue independent choices and cater to the demands of their jobs. Often, the lack of agency results in them quitting the workforce or opting for positions below their qualifications.

- Occupation segregation - Owing to the limitations set by their families and society in general, women are educated and skilled in certain specific sectors like the beauty industry, teaching etc. As a result, while women dominate these sectors, it further excludes them other opportunities. The increased competition to work in these limited sectors also lead to reduction in wages, and limited career growth.

- Socio-economic status of the women - The economic and social background plays an essential role in defining the education and job prospects available to women. In most situations, women from low economic backgrounds have limited access to education and training but are allowed to work to add to the household income. However, women from affluent families are allowed to pursue education at their will but do not have a similar freedom with respect to pursuing a career.

Keeping in mind the complexities leading to the drop in FLFPR and the decline in the job creation, the obvious question is why do we need women in the workforce? In July last year, The Economist did a cover story on how India is losing 235 million employees because of the gap between the male and female labour force participation rates. This additional number of working population, as per the International Monetary Fund's (IMF) chief Christine Lagarde, would make India $27 \%$ richer. Two ways in which women in the workforce can help the economy are:

- by increasing the consumption and therefore the production in the economy, and

- by creating additional jobs in the household economy.

India is a consumer-based economy - its growth is largely driven by the consumption of goods and services within the economy. A rise in consumption stimulates demand for the goods and services leading to a hike in their supply and the creation of new jobs. With more women earning, there would be an increase in the spending capabilities at both the individual and the household level. This would expand the supply of goods and services creating an impetus for more jobs. In order to encourage more women to join the workforce, we need to create policy changes that incentivise their participation. Promoting pay parity and creating a safe environment at the workspace are basic steps that need to be taken in order to increase the FLFPR. Another advantage of having more women in the workforce is that it helps create jobs in the household economy. One of the most common arguments against letting women work is that it would hamper the household economy predominately managed by them. Right from cooking and cleaning to stocking food and managing assets at home, women oversee varied tasks to maintain a functioning household, often referred as unpaid housework. Based on the calculation by the United Kingdom's Office for National Statistics, unpaid household work and childcare was worth 1 trillion pounds (\$1,289 billion) in 2016. However, instead of creating market value for such jobs by outsourcing them, these tasks are 
managed primarily by women across economic groups in the country. A large number of women stepping out of their houses would increase household income and create opportunities for jobs in household care like cleaning, cooking etc. Along with increasing the number of women in the workforce, it would also provide scope to market unpaid housework and allow the economy to capture the value generated by these activities.

\section{IMPACT OF COVID ON WORKING WOMEN}

According to a Zinnov-Intel 2019 Gender Diversity Study, the representation of women in corporate India has risen from $21 \%$ over five years to $30 \%$. Women entrepreneurs and start-up founders, in particular, are scripting their own opportunities.

In the last decade alone (2010-2020), there has been a phenomenal 11X increase in the number of women entrepreneurs in tech, according to a recent survey by MAKERS India, a digital platform advancing equality at the workplace. But this momentum has hit a serious speedbump. The pandemic has left working women vulnerable. Centre for Monitoring Indian Economy (CMIE) data shows that far fewer women who lost work during the lockdown period were able to come back to work once the lockdown was lifted. Worse, by August 2020, only 40\% of the women employed in December 2019 were still employed, versus $88 \%$ of men, according to CMIE.[4]

Like elsewhere in the world, women here are looking to employers for crucial support that can keep them on the career map. Let's face it, the juggling act working women sign up for isn't all that different whether you are in the Bay Area or Bangalore.

But in the fallout of the Covid crisis, a bad situation has become much worse. McKinsey, reporting on the 'double shift' women notoriously work across the world, finds that in India, women do almost 'ten times as much unpaid care work as men' -- through the pandemic, such work fell disproportionately to women with children at home. For India particularly, there's an economic advantage to support and level the playing field for women in the workforce. Women account for almost half (48\%) of India's population, but female participation in the labour force is $\sim 20 \%$, the lowest in South Asia. Pushing women's participation up to the global average of 48 percent in the next 10 years can add another USD 700 billion to GDP growth, according to Niti Aayog.[2-4]

\subsection{Post Covid world: Benefits of Inclusion}

Research shows diversity and inclusion enable high-performing teams and fuel innovation, leading to better financial performance. Especially in technology, different mindsets and styles of working can better reflect the diverse user or client base that global companies have. As enterprises grapple with challenges brought on by the pandemic, more 'inclusive' thinking with diverse voices and ideas in the room, could hold the answer to new solutions. Wharton School researchers have found that inclusive companies are better positioned to conquer the "three P's" that matter in a post-Covid world 'performance, preparedness, and purpose'.

\section{MAKING LEAP FOR MORE INCLUSIVE WORKFORCE FOR INDIA}

By empowering and supporting many more women to be aatmanirbhar, to enter the workforce, to stay in the workforce, and to take a seat at the table. 


\subsection{Empowering Women at the workplace}

Companies globally are stepping up to create a more inclusive culture. I see it in how they are reframing policies that offer flexibility for women, in how they are nurturing female leaders, supporting new mothers, creating pathways for women to re-enter the workforce, and bringing pay parity.

I believe each of these ideas has an urgent place in the Indian workplace too, with one more that I have personally relied on in my career -- mentoring. Women need to speak to and speak up for other women to help them believe in themselves and dream big!

\subsection{Nurturing a community to grow the women's movement}

For a wider, accelerated change, many more women (and men) in the country will have to come together to challenge the status quo. A UPenn study has found that the tipping point for social change comes when $25 \%$ of people in a group adopt a new social norm. India needs a larger community to achieve this critical mass, to push for more inclusive policies nationally and in workplaces across the country -- a community that can fight discrimination, that can fuel the debate on inclusion, that can be a support network for women and find new solutions for a more genderbalanced workplace.

\subsection{Everybody in: Digital inclusion for self-reliance}

There is a lot of distance to cover before the women's movement extends beyond India's cities to transform the lives of women in the remotest corners of the country. As a Deloitte report pointed out, women in India -- like other developing countries of the world -- are held back by a lack of access to quality education and the digital divide (starkly exposed by the pandemic). This hinders building skills that can increase their employability or help them establish their own business. Through the Skill India Mission, the government is already taking steps to help women boost entrepreneurial skills and relevant job capabilities. 'Self-reliant' women will go a long way to realize the state's vision of 'AatmaNirbhar'India.[6-8]

"Given the country's high mobile internet penetration, India also has the opportunity to empower women through enhanced digital literacy and access."

The 2021 Union budget acknowledged the need for greater inclusion in India's workforce by expanding social security benefits to gig workers. This, for example, could open new pathways for Indian women who want to enter the workforce through digital platforms, if they have the right digital preparedness. Many more Indian women must also be able to use the Internet as a force for change to build the skills they need, but also to tell their stories -- the power of every voice amplified in a digital world. Indian women are ready for more. But a lot needs to be done to drive positive change. A nation has to come together the government, private sector, citizens to rethink the role and contribution of women in Indian society. The chorus of voices that can lead to dialogue, action, and finally, change, has to grow louder.[8]

\section{POSSIBILITIES FOR WOMEN IN POST COVID WORLD}


The global spread of the coronavirus, the consequent lockdown in many countries, and adherence to norms like self-isolation and social distancing has created an added opportunity for women who had quit the workforce owing to 'household responsibilities'. The flexibility that remote working brings will allow women to balance their work and life better. Several tech companies are also leaning to hire remote workers on full-time payroll, which was not the case even a year ago. In fact, in the present scenario is proving to be more productive and a lot of companies are planning to adopt a wider use of this model even after COVID-19. This opens up the market for diverse tech talent, where companies look for talent in locations where they don't have a physical office. Considering all of this, let's talk about ways in which women can take advantage of this situation. [4-9]

5.1 Rejoining workforce: The coronavirus pandemic has hit women worldwide with job losses and closures of childcare centres. Yet a surprising bright spot is emerging: India's \$200 billion technology services industry, where new rules are expected to provide female workers with a broad swath of flexible work arrangements and fresh employment opportunities. As per the report by online career platform 'JobsForHer', 'work-for-home jobs' posted on its platform saw 30 per cent rise in March 2020 as compared to the same month last year. The number of women looking to start or restart their careers has also risen dramatically in recent times. Women today are highly motivated and despite the world almost coming to a halt, they are still pursuing opportunities. The work-from-home comes as a blessing for those women who had to leave their jobs owing to prior familial commitments. [9-12]

5.2 Reskilling/Upskilling: COVID-19 has brought light to the ever changing and shape-shifting nature of the economy. Upskilling is the order of the day whether it's because industries have been pivoting or people are being laid off and the new normal means that certain skills are and will be highly sought in the post COVID-19 world, given that many of our usual ways of living have changed. Employees all over the world are being compelled to adjust to digital infrastructure and work remotely. This means acquiring new skills, not just technical but also soft skills to make a smooth transition into the new way of working. According to LinkedIn's Workforce Confidence Index survey, nearly 64 percent corporate respondents are planning to focus on learning new skills with a focus toward tech skills with courses on Artificial Intelligence, Machine Learning, Data Science \& Analytics \& Data Engineering gaining traction. With the dynamics of the changing world, it is the perfect time for women to reskill themselves and get out there and make the most of the work from home opportunity. If COVID has thrown your job, company or career for a toss, this might be the moment to think about not just a next move, but a larger career change. Instead of struggling to retain status quo, embrace the chaos. Technology can help address some of the obstacles in making a mid-career shift - especially right now, when so much of the professional world has moved entirely online out of necessity. In the present circumstances, coding is proving to be the new career choice for many women and rightfully so. Education platforms are helping women learn to code and start a career from their homes thus allowing them to cross financial and location barriers to achieve their dream of becoming great software developers. Apart from this, teaching is also becoming one of the most sought-after job roles for women. Teaching in its online avatar helps address women specific concerns, like care-giving responsibilities, lack of safe public and workspaces, and the inability to move to cities.[11-12]

\section{CONCLUSION}


The global spread of the coronavirus, the consequent lockdown in many countries, and adherence to norms like self-isolation and social distancing has created an added opportunity for women who had quit the workforce owing to 'household responsibilities'. The flexibility that remote working brings will allow women to balance their work and life better. There are ways in which women can take advantage of this situation as silver lining. We in this research paper have gone into the set of oppurtunities which can be grabed by the women of this country to improve their situation in societal, economic and cultural aspects. This will even improvise the situation of country as well, which strugling in many ends. Indian women are ready for more. But a lot needs to be done to drive positive change. A nation has to come together, the government, private sector, citizens to rethink the role and contribution of women in Indian society. The chorus of voices that can lead to dialogue, action, and finally, change, has to grow louder

\section{REFERENCES}

1. Action Aid. (2019). Invisible work invisible workers: The sub-economies of unpaid work and paid work action research on women's unpaid labour. Johannesburg: Action Aid.

2. https://www.indiabudget.gov.in/economicsurvey/

3. Alon, T. M., Doepke, M., Olmstead-Rumsey, J., \& Tertilt, M. (2020). The impact of COVID19 on gender equality. Cambridge: National Bureau of Economic Research.

4. 'Unemployment Rate in India' , by Centre for Monitoring Indian Economy Pvt. Ltd. ; https://unemploymentinindia.cmie.com/kommon/bin/sr.php?kall=wtabnav\&tab=4080

5. Bittman, M., England, P., Sayer, L., Folbre, N., \& Matheson, G. (2003). When does gender trump money? Bargaining and time in household work. American Journal of Sociology, 109(1), 186-214.

6. Brines, J. (1994). Economic dependency, gender, and the division of labor at home. American Journal of Sociology, 100(3), 652-688.

7. Cofey, C., Revollo, P. E., Harvey, R., Lawson, M., Butt, A. P., Piaget, K., et al. (2020). Time to care: Unpaid and underpaid care work and the global inequality crisis. Nairobi: Oxfam International.

8. https://prsindia.org/budgets/parliament/union-budget-2021-22-analysis

9. Dutta, D. (2019). No work is easy! Notes from the feld on unpaid care work for women. In O. India (Ed.), Mind the gap: The state of employment in India (pp. 98-125). New Delhi: Oxfam India.

10. Ferrant, G., Pesando, L. M., \& Nowacka, K. (2014). Unpaid care work: The missing link in the analysis of gender gaps in labour outcomes. Paris: OECD Development Centre. 
11. Frankiewicz, B. (2020). 5 ways we lack gender balance in the workplace. World Economic Forum. https://www.weforum.org/agenda/2020/01/5-ways-companies-can-progress-morewomen-intoleadership-roles/. Retrieved July 15, 2020.

12. Greenstein, T. N. (2000). Economic dependence, gender, and the division of labor in the home: A replication and extension. Journal of Marriage and Family, 62(2), 322-335.

13. Grown, C., \& Sánchez-Páramo, C. (2020). The coronavirus is not gender-blind, nor should we be. World Bank Blogs. https://blogs.worldbank.org/voices/coronavirus-not-gender-blind-norshoul d-we-be. Retrieved July 15, 2020.

14. Hirway, I. (2012). Missing labour force: An explanation. Economic and Political Weekly, 47(37), 67-72. 